\title{
Factors associated with the compliance of recommended first postnatal care services utilization among reproductive age women in Benin Republic: an analysis of 2011/2012 BDHS data
}

\author{
Justin Dansou1*, Adeyemi O. Adekunle², Ayodele O. Arowojolu²
}

\author{
${ }^{1}$ Pan African University Institute of Life and Earth Sciences (PAULESI), University of Ibadan, Ibadan, Nigeria \\ ${ }^{2}$ University College Hospital, University of Ibadan, Ibadan, Nigeria
}

Received: 14 January 2017

Revised: 10 February 2017

Accepted: 27 February 2017

\author{
*Correspondence: \\ Justin Dansou, \\ E-mail: djustino87@gmail.com
}

Copyright: (C) the author(s), publisher and licensee Medip Academy. This is an open-access article distributed under the terms of the Creative Commons Attribution Non-Commercial License, which permits unrestricted non-commercial use, distribution, and reproduction in any medium, provided the original work is properly cited.

\begin{abstract}
Background: High maternal and neonatal mortality persist in Benin republic. Rates of decline are slow and factors influencing PNC services utilization are not well known. This study aims to assess factors associated with PNC services utilization among mothers and their newborns with special focus on the recommendation 2 of WHO guidelines on postnatal care of the mother and the newborn.

Methods: This study analysed Benin's 2011/2012 DHS data. A total of 16,599 women were interviewed where 8,275 eligible for the present study. Multinomial logistic regression was applied.

Results: While $68.42 \%$ of mothers and their newborns received at least one PNC visit over postnatal period, the percent of newborns and their mothers with appropriate first PNC check-up was low, 19.95\%. Factors explaining PNC uptake were place of residence, ethnic group, occupation, ANC attendance, place of delivery, baby birth size, household wealth status, mass media use, and to a lesser extent education attainment. Accessibility, number of living children followed by the birth order number, and desire for pregnancy appeared to be specific determinants to appropriate first PNC check-up. Mothers who attended more frequently ANC services were more likely to receive PNC check-ups. Mothers who delivered at private health facility were more likely to receive PNC check-ups.

Conclusions: To increase the achievement of the recommended WHO PNC frequency, there is a need to: address unmet needs for Family Planning in Benin; to expend health education and counselling to encourage ANC attendance supervise by skilled personnel.
\end{abstract}

Keywords: Appropriate first PNC, Benin, Mother and newborn care, Postnatal care, WHO recommended PNC

\section{INTRODUCTION}

Global progress over MDGs time showed that maternal and child mortality has dropped nearly $50 \%$ since the 1990s. ${ }^{1,2}$ Despite such success, number of women and newborns continue to die unnecessarily every day from largely preventable causes ${ }^{1,3}$ especially in sub-Saharan Africa (SSA). For example, among maternal deaths recorded worldwide in 2015, SSA alone accounts for roughly $66 \% .^{3}$ On the other hand, stillbirth rates did not measurably change over MDGs time. ${ }^{1}$ Most of maternal and newborn deaths occur during postnatal period (first 6-8 weeks after delivery) known as a critical period affected by major changes which determine the wellbeing and lives of both mother and newborn, ${ }^{2,4-7}$ in case of lack of appropriate care. ${ }^{4,8}$ In low and middle income countries, $74.3 \%$ of the total deaths during the neonatal period occur in the first week of life. ${ }^{4}$ 
In response to preventable maternal and newborn mortality, the World Health Organization promotes basic postnatal care (PNC) recommendations addressing timing, number and place of postnatal contacts and content of PNC for all mothers and babies during postnatal period. ${ }^{4}$ The recommendation 2 of the guidelines suggests that mothers and their newborns should receive PNC in the facility for at least 24 hours after delivery if the birth took place in a health facility. If the birth is at home, the first PNC should be within 24 hours of birth.

However, along the continuum of care, significant disruptions occur in the continuity of services where postnatal period is known as the most neglected period for provision of quality care than pregnancy and childbirth and related programmes are among the weakest of all reproductive and child health programmes in Africa. ${ }^{4,7,9}$ Global estimates showed that over two third of newborns deaths could be saved through existing maternal and child health programmes. ${ }^{6,10}$ PNC coverage at $90 \%$, could allow avert up to 10 to $27 \%$ of newborns deaths. ${ }^{10}$ However, evidence is not completely consistent: while some studies provide strong evidence of the link between PNC attendance and neonatal survival, others have found no or weak associations..$^{11-15}$

Several studies in low and middle income countries have identified factors associated with PNC uptake. They were: household wealth status; maternal education attainment; ANC utilization; desire of pregnancy; ethnic; distance to health facilities; place of residence; place of delivery; newborn's health status after delivery. ${ }^{9,16-18}$ Despite such findings, evidences are inconsistent. While study from Kanté et al found significant association with ANC attendance and household income, Mohan and colleagues found no or weak association. ${ }^{9}$ In addition, factors pertaining to supply and demand side of health services, attitudes towards maternal PNC services and perception on quality of health services in health facilities, and the state of roads (routes), the availability of transport for emergencies were found to be strong predictors for PNC seeking. ${ }^{17,19}$

Benin Republic is one of the countries where high maternal and child mortality persist. The number of maternal deaths for 100,000 live births has declined only from 576 to 405 between 1990 and 2015 with the persistence of high fertility estimated at 4.9 children per woman in 2015, despite recent efforts. For instance, through the decree number 2008-70 of December 22, 2008, the government has set free caesarean section. ${ }^{3,20,21}$

The rate of achieving at least one ANC visits in Benin Republic was $86 \%$ while $84 \%$ delivered with a skilled birth attendant and $68 \%$ received at least one PNC regardless of the time after delivery (51\% received PNC visit within the 48 hours after birth as recommended by WHO. It is showed that while about three fourth (77\%) of Beninese populations dwell at less than 5 kilometre from health facility, only two fifth (44\%) uses health facilities and about $22 \%$ of deliveries still take place at home without skilled attendance, especially in the northern part of the country. ${ }^{22}$ Yet, around $10 \%$ of newborn in every country need assistance to begin breathing. ${ }^{2}$ However, studies examining utilization of health services in Benin republic in general, and especially by mothers and their newborns during postnatal period are scarce.

The few that have looked to the issue, were done at local geographic level and even have looked at health services utilization in general. ${ }^{23,24} \mathrm{~A}$ study at national level is important as it may help in directing policies aiming the improving of PNC services uptake. With regards to PNC initiation according to Global Experts' recommendations, studies are also very scarce, especially in Benin republic. This study attempts to determine the extent to which reproductive age mothers who had recently completed pregnancy and their newborns received first PNC.

It has the potential to identify the factors associated with the appropriate PNC services initiation vs nonappropriate PNC uptake by examining the extent to which mothers after delivery go back (when delivered at health facility) or seek first PNC checks (for delivery at home) at a health facility with compliance of the recommendation 2 of WHO guidelines on postnatal care for the mother and the newborn. ${ }^{4}$ These factors, once well-known will give clues on how the issues can be tackled. Although PNC services could be provided to both women and newborns at three different levels namely PNC at the facility level, PNC as outreach (Home visits by a skilled attendant), and PNC at the family and community level, the focus of this study is to examine the issue at the level of health facility.

\section{METHODS}

\section{Data and study population}

Data are from the fourth Benin Demographic and Health Survey (BDHS) conducted in 2011-2012. Using a nationally representative sample the Measure DHS collects data on reproductive age women (15-49 years) on many topics including reproductive health. The sample for this analysis included mothers who had completed at least a pregnancy within the five years preceding the fourth BDHS. A total of 16,599 women were interviewed at the survey while 9,111 gave birth within the 5 years preceding the survey where 8,275 were included in this study.

\section{Outcome variable}

The outcome of this study was utilization of PNC services with compliance of recommendation 2 of WHO guidelines on PNC (4). WHO's recommendation 2 suggests, amongst other, that mothers and newborns should be assessed in a facility for at least 24 hours after birth if the birth took place in a health facility. If the birth 
is at home, the first postnatal contact should be within 24 hours of birth and a minimum of three additional PNC for all mothers and newborns, on day 3 (48-72 hours), between days 7-14 after birth, and six weeks after delivery.

Since this study aims to understand the extent to which mothers and their newborns get to a health facility after delivery for the only one and unique purpose of PNC checks, first PNC contacts at a health facility (for deliveries at a health facility) before discharge were not considered. In addition, mothers who delivered at a health facility and were not discharged at or on the third day of delivery were dropped.

Mothers were considered to have made appropriate utilization of first PNC services if she and her baby were checked by a qualified health care provider on or before the third day of delivery (delivery at a health facility), after being previously discharged. For mother who gave birth at home, she was considered to have made appropriate utilization of PNC services if she and her babies were checked by a qualified health care provider at a health facility within the 24 hours following the birth. The outcome was, then, categorized as 1. No_PNC, 2. Some_level_of_PNC and 3. Appropriate_First_PNC.

\section{Independent variables}

Correlates of PNC seeking were selected based on the literature. They were: age group at the birth of child, education, occupation, religion, Ethnic groups, household wealth quintiles, sex of head of household, area, place of residence, desire of pregnancy, frequency of ANC visits, sex of child, birth size, place of delivery, and the rank of birth.

A combined indicator of health facility accessibility level, based on geographical, financial and cultural accessibility such as distance to health facility, getting money needed for treatment and getting permission to go was created using principal component analysis (PCA) methods. Also, an indicator of mass media exposure, based on frequency of exposition to media such as radio, television and newspaper/magazine was created using PCA methods.

\section{Statistical analysis}

Three levels of analysis were performed: univariate (percentage distribution of study sample by study variables) bivariate (pairwise associations between variables), and adjusted multinomial logistic modelling used to calculate the net measures of association (Relative Risk Ratio: RRR), between each of the independent variables and the likelihood of mothers seeking PNC services.
Analyses were completed using the software STATA 12.0. Differences were tested for significance at a $5 \%$ significance level.

The International Review Board of Macro International and the Comité National d'Ethique pour la Recherche en Santé of Benin have all approved the fourth BDHS's tools before the survey were conducted. Participation in the DHS was entirely voluntary and respondents signed an informed consent form preceding the interview. In order to access the data from DHS MEASURE web site a written request was submitted to DHS MACRO and permission was granted to use the data.

\section{RESULTS}

\section{Sample characteristics and utilization of postnatal care (PNC) services}

The average age of the mothers at the birth of children was $27.85 \pm 0.14$ years while $59.7 \%$ was living in monogamous unions. Most mothers were uneducated $(73.1 \%)$, delivered their youngest children in public health facility $(75.8 \%)$ where $18.0 \%$ was first-born, lived in rural area $(63.0 \%)$ and $45.2 \%$ had a low/none access to mass media. There were 8 ethnic groups represented in the sample, predominantly Fon (40.7\%), followed by Adja (15.3\%), Yoruba (11.1\%), and Bariba (10.0\%). More than half percent $(52.1 \%)$ of mothers were declared to be Christian.

With regards to the outcome, the compliance with the first postnatal check-ups as outlined in recommendation 2 of the WHO guidelines on postnatal care of the mother and the newborn were uncommon in Benin. Only $19.9 \%$ mothers had appropriate first PNC check-up, $48.5 \%$ some level of PNC while, $31.6 \%$ had no PNC check-up (Table 1). ${ }^{4}$

\section{Factors associated to first PNC services utilization}

Table 2 presents results of multivariate analyses. In the adjusted models factors associated to PNC check-ups were respondent's occupation, ethnic group, household wealth status, area, accessibility, mass media use, number of living children, desire for pregnancy, ANC frequency, birth order number, place of delivery, and child's birth size. Marital status, sex of household head, sex of child, religion, accessibility and mother's age at the birth of their child were not associated to PNC visits attendance.

Mothers and newborns that lived in households with rich or richest wealth index were more likely to receive PNC check-up compared to their counterpart from others households. The chance to receive PNC check-up (the appropriate first PNC or not) increases continually with the household wealth quintiles. [For appropriate first PNC, aRRR Richer $=1.65$, 95\% CI 1.28-2.12; aRRR Richest $=2.22,95 \%$ CI $1.58-3.14]$. 
Table 1: Sample distribution $(n=8,275)$.

\begin{tabular}{|c|c|c|c|}
\hline Variables & Category & Frequency & Percentage $(\%)$ \\
\hline \multirow{4}{*}{$\begin{array}{l}\text { Age at the birth of child (mean: } \\
27.85 \pm 0.14 \text { ) }\end{array}$} & $<19$ years & 734 & 8.9 \\
\hline & $20-24$ years & 2,015 & 24.3 \\
\hline & 25-34 years & 4,163 & 50.3 \\
\hline & 35 years + & 1,363 & 16.5 \\
\hline \multirow{3}{*}{ Education } & No education & 6,084 & 73.5 \\
\hline & Primary & 1,304 & 15.8 \\
\hline & Secondary or plus & 887 & 10.7 \\
\hline \multirow{4}{*}{ Type of union } & Monogamous & 4,944 & 59.7 \\
\hline & Polygamous (1 other wife) & 1,987 & 24.0 \\
\hline & Polygamous ( 2 or More other wives) & 808 & 9.8 \\
\hline & Never married & 536 & 6.5 \\
\hline \multirow{5}{*}{ Occupation } & Not working & 2,932 & 35.4 \\
\hline & White collar & 210 & 2.6 \\
\hline & Sales/services & 3,018 & 26.5 \\
\hline & Agriculture & 1,608 & 19.4 \\
\hline & Manual/domestic & 507 & 6.1 \\
\hline \multirow{4}{*}{ Religion } & Traditional & 1,343 & 16.2 \\
\hline & Muslim & 2,182 & 26.4 \\
\hline & Christian & 4,309 & 52.1 \\
\hline & No religion & 441 & 5.3 \\
\hline \multirow{6}{*}{ Ethnic group } & Adja & 1,225 & 14.8 \\
\hline & Bariba & 863 & 10.4 \\
\hline & Betamaribe & 674 & 8.1 \\
\hline & Fon & 3,365 & 40.7 \\
\hline & Yoruba & 919 & 11.1 \\
\hline & Other & 1,229 & 14.9 \\
\hline \multirow{5}{*}{ Wealth quintiles } & Poorest & 1,846 & 22.3 \\
\hline & Poorer & 1,792 & 21.7 \\
\hline & Middle & 1,783 & 21.5 \\
\hline & Richer & 1,622 & 19.6 \\
\hline & Richest & 1,232 & 14.9 \\
\hline \multirow{2}{*}{ Household head } & Male & 7,240 & 87.5 \\
\hline & Female & 1,035 & 12.51 \\
\hline \multirow{7}{*}{ Area } & Atacora/Donga & 1,346 & 16.3 \\
\hline & Littoral (Cotonou) & 667 & 8.1 \\
\hline & Borgou/Alibori & 1,378 & 16.6 \\
\hline & Mono/Couffo & 1,126 & 13.6 \\
\hline & Oueme/Plateau & 1,469 & 17.8 \\
\hline & Zou/Collines & 1,400 & 16.9 \\
\hline & Atlantique & 889 & 10.7 \\
\hline \multirow{2}{*}{ Residence } & Urban & 3,064 & 37.0 \\
\hline & Rural & 5,211 & 63.0 \\
\hline \multirow{3}{*}{ Mass exposure } & Lower/none & 3,780 & 45.7 \\
\hline & Moderate & 2,670 & 32.3 \\
\hline & Higher & 1,825 & 22.0 \\
\hline \multirow{2}{*}{ Accessibility } & Big problem & 4,159 & 50.3 \\
\hline & Not a big problem & 4,116 & 49.7 \\
\hline \multirow{3}{*}{ Number of living children } & Less than 3 & 3,256 & 39.3 \\
\hline & $3-5$ & 3,870 & 46.8 \\
\hline & 6 or more & 1,149 & 13.9 \\
\hline \multirow{2}{*}{ Birth order number } & First birth & 1,485 & 18.0 \\
\hline & $2-4$ & 4,288 & 51.8 \\
\hline
\end{tabular}


Table 1: Sample distribution $(n=8,275)$.

\begin{tabular}{|c|c|c|c|}
\hline Variables & Category & Frequency & Percentage $(\%)$ \\
\hline Birth order number & 5 or more & 2,502 & 30.2 \\
\hline \multirow{3}{*}{ Desire of pregnancy } & Desire before & 6,642 & 80.3 \\
\hline & Desire later & 1,095 & 13.2 \\
\hline & No desire & 538 & 6.5 \\
\hline \multirow{4}{*}{ Number of ANC attended } & No ANC & 1,069 & 12.9 \\
\hline & Less than 4 & 2,235 & 27.0 \\
\hline & 4 or more & 4,639 & 56.1 \\
\hline & Don’t know & 332 & 4.0 \\
\hline \multirow{3}{*}{ Place of delivery } & Public health facility & 6,274 & 75.8 \\
\hline & Private health facility & 831 & 10.1 \\
\hline & Non-health facility & 1,170 & 14.1 \\
\hline \multirow{4}{*}{ Birth size } & Large than average & 1,426 & 17.2 \\
\hline & Average & 5,384 & 65.1 \\
\hline & Smaller than average & 985 & 11.9 \\
\hline & Don’t know & 480 & 5.8 \\
\hline \multirow{3}{*}{ PNC services utilization } & No PNC & 2,613 & 31.6 \\
\hline & Some level of PNC & 4,011 & 48.5 \\
\hline & Appropriate First PNC & 1,651 & 19.9 \\
\hline Total & & 8,275 & \\
\hline
\end{tabular}

The relative risk to receive PNC check-up by mothers and newborns who lived in urban area [for appropriate first PNC aRRR=1.60, 95\% CI 1.34-1.89; for some level of PNC aRRR=1.24 95\% CI 1.08-1.43] was higher than that of mothers and newborns dwelling in rural area. Mothers who declared not working or were in manual and domestic working were less likely to receive PNC check-up for themselves and their newborns, compared to those in the agriculture sector.

When the pregnancy was desired, mothers and newborns were more likely to receive appropriate first PNC visit [aRRR $=1.42,95 \%$ CI 1.04-1.93]. Mothers with higher rank of birth were less likely to receive appropriate first PNC $[\mathrm{aRRR}=0.66,95 \% \mathrm{CI} 0.53-0.83]$. With regards to mass media exposure, it improves PNC check-ups [for appropriate first PNC aRRR 1.30, 95\% CI 1.10-1.54].

Chances for PNC check-ups were much higher when mothers met the WHO recommended minimum 4 ANC visits. For appropriate first PNC aRRR (less than 4 visits was) $=3.69$, 95\% CI 2.57-5.30; and aRRR (4 or more ANC visits) $=4.47,95 \%$ CI 3.12-6.39. When the delivery occurred at a health facility (public or private), the chances to go back after discharging for PNC check-ups were higher especially in receiving appropriate first PNC services, compared to those who delivered outside health facility.

Chances were much higher when deliveries took place at a private health facility than when they took place in a public health facility. While the relative risk to receive
PNC visit among private health facility deliveries were 13.5 (95\% CI 8.27-22.05), that of public health facility deliveries were 12.50 (95\% CI 8.16-19.16).

\section{DISCUSSION}

This study examined factors associated with the utilization of postnatal care services. Past studies used to assess factors associated with the use of PNC services over postnatal period in general. Few studies have looked at the compliance with the recommended WHO frequency of PNC. This study, has paid special attention to the compliance with the first PNC visit as outlined in the recommendation 2 of WHO's new guidelines of postnatal care of mothers and newborns. ${ }^{4}$ The findings show that the uptake of appropriate first postnatal care utilization as defined in this study is low in Benin Republic (19.95\%). According to the place of delivery, profound inequalities were noticed in achieving such care (2.22\% among deliveries that took place at home against $22.73 \%$ and $23.95 \%$ for public health facility and private health facility delivery, respectively. However, the rate of achieving at least one PNC visits over postnatal period was $68.42 \%$. In agreement with past studies, ${ }^{16-18}$ the place of delivery emerged as a significant and important factor for PNC services utilization especially for appropriate first PNC seeking in Benin republic. Evidences are, however, inconsistent. Moreover, mothers who delivered at private health facility were more likely to seek PNC services, than those who delivered at public health facility. ANC visits frequency during pregnancy also emerged as a significant positive determinant to postnatal services uptake as previously reported. ${ }^{16-18}$ 
Table 2: Adjusted relative risk ratio (aRRR) and $95 \%$ confidence interval of first PNC services utilization $(\mathbf{n}=\mathbf{8 , 2 7 5})$.

\begin{tabular}{|c|c|c|c|}
\hline Variables & Category & $\begin{array}{l}\text { No PNC VS Some level of } \\
\text { PNC }(95 \% \text { CI })\end{array}$ & $\begin{array}{l}\text { No PNC VS Appropriate } \\
\text { first PNC ( } 95 \% \text { CI })\end{array}$ \\
\hline \multirow{4}{*}{ Age } & $<19$ years & Ref & Ref \\
\hline & 20-24 years & $0.95(0.76-1.20)$ & $1.02(0.76-1.35)$ \\
\hline & 25-34 years & $1.01(0.79-1.29)$ & $1.14(0.84-1.54)$ \\
\hline & 35 years+ & $1.01(0.75-1.35)$ & $1.29(0.90-1.85)$ \\
\hline \multirow{3}{*}{ Education } & No education & Ref. & Ref. \\
\hline & Primary & $1.09(0.92-1.30)$ & $1.16(0.95-1.85)$ \\
\hline & Secondary or plus & $1.26(0.98-1.61)+$ & $1.30(0.98-1.72)+$ \\
\hline \multirow{4}{*}{$\begin{array}{l}\text { Type of } \\
\text { union }\end{array}$} & Monogamous (No other wife) & Ref. & Ref. \\
\hline & Polygamous ( 1 other wife) & $1.01(0.88-1.16)$ & $1.0(0.84-1.18)$ \\
\hline & Polygamous ( 2 or More other wives) & $0.89(0.73-1.08)$ & $0.87(0.68-1.10)$ \\
\hline & Never married & $1.04(0.80-1.36)$ & $0.91(0.66-1.25)$ \\
\hline \multirow{5}{*}{ Occupation } & Not working & $0.66(0.56-0.78)^{* * *}$ & $0.70(0.57-0.86)^{* *}$ \\
\hline & White collar & $1.07(00.65-1.76)$ & $1.32(0.76-2.29)$ \\
\hline & Sales/services & $0.84(0.72-1.00)^{*}$ & $0.73(0.59-0.90)^{*}$ \\
\hline & Agriculture & Ref. & Ref. \\
\hline & Manual/domestic & $0.66(0.51-0.87)^{* *}$ & $0.54(0.39-0.75)^{* * *}$ \\
\hline \multirow{3}{*}{ Religion } & Traditional & Ref. & Ref. \\
\hline & Muslim & $0.97(0.78-1.24)$ & $1.33(0.84-1.53)$ \\
\hline & Christian & $1.03(0.88-1.20)$ & $1.04(0.86-1.26)$ \\
\hline \multirow{6}{*}{ Ethnic group } & Adja & $0.85(0.63-1.14)$ & $1.09(0.78-1.53)$ \\
\hline & Bariba & $0.68(0.48-0.96)$ & $0.93(0.61-1.43)$ \\
\hline & Betamaribe & $1.48(1.03-2.15)^{*}$ & $2.56(1.64-4.01)^{* * *}$ \\
\hline & Fon & Ref. & Ref. \\
\hline & Yoruba & $1.55(1.23-1.95)^{* * *}$ & $1.66(1.26-2.19)^{* * *}$ \\
\hline & Other & $0.72(0.52-0.98)^{*}$ & $0.75(0.51-1.09)$ \\
\hline \multirow{5}{*}{$\begin{array}{l}\text { Wealth } \\
\text { quintiles }\end{array}$} & Poorest & Ref. & Ref. \\
\hline & Poorer & $1.01(0.86-1.19)$ & $0.90(0.72-1.13)$ \\
\hline & Middle & $1.05(0.89-1.25)$ & $1.32(1.06-1.65)^{*}$ \\
\hline & Richer & $1.49(1.21-1.82)^{* * *}$ & $1.65(1.28-2.12)^{* * *}$ \\
\hline & Richest & $1.98(1.47-2.63)^{* * * *}$ & $2.22(1.58-3.14) * * *$ \\
\hline \multirow{2}{*}{$\begin{array}{l}\text { Household } \\
\text { head }\end{array}$} & Male & Ref. & Ref. \\
\hline & Female & $0.90(0.75-1.08)$ & $0.93(0.75-1.16)$ \\
\hline \multirow{7}{*}{ Area } & Atacora/Donga & $1.97(1.33-2.90)^{* *}$ & $1.55(0.99-2.44)+$ \\
\hline & Littoral (Cotonou) & Ref. & Ref. \\
\hline & Borgou/Alibori & $1.50(1.01-2.21)^{*}$ & $1.05(0.66-1.65)$ \\
\hline & Mono/Couffo & $1.03(0.70-1.52)$ & $1.37(0.88-2.11)$ \\
\hline & Oueme/Plateau & $1.37(1.01-1.86)^{*}$ & $0.75(0.52-1.06)$ \\
\hline & Zou/Collines & $1.75(1.27-2.41)^{* *}$ & $2.46(1.72-3.51)^{* * *}$ \\
\hline & Atlantique & $0.65(0.48-0.89)$ & $0.81(0.57-1.14)$ \\
\hline \multirow{2}{*}{ Residence } & Urban & $1.24(1.08-1.43)^{* *}$ & $1.60(1.34-1.89)^{* * *}$ \\
\hline & Rural & Ref. & Ref. \\
\hline \multirow{3}{*}{$\begin{array}{l}\text { Mass media } \\
\text { exposure }\end{array}$} & Lower/none & Ref. & Ref. \\
\hline & Moderate & $1.31(1.15-1.50)^{* * *}$ & $1.30(1.10-1.54)^{* *}$ \\
\hline & Higher & $1.16(0.96-1.40)$ & $1.18(0.94-1.48)$ \\
\hline \multirow{2}{*}{ Accessibility } & Big problem & Ref. & Ref. \\
\hline & Not a big problem & $0.91(0.81-1.03)$ & $1.00(0.87-1.16)^{*}$ \\
\hline \multirow{3}{*}{$\begin{array}{l}\text { Number of } \\
\text { living } \\
\text { children }\end{array}$} & Less than 3 & $0.89(0.76-1.05)$ & $0.86(0.70-1.05)$ \\
\hline & $3-5$ & Ref. & Ref. \\
\hline & 6 or more & $1.03(0.84-1.27)$ & $1.31(1.00-1.71)^{*}$ \\
\hline \multirow{2}{*}{$\begin{array}{l}\text { Birth order } \\
\text { number }\end{array}$} & First birth & $1.19(0.98-1.44)+$ & $1.25(0.99-1.58)+$ \\
\hline & $2-4$ & Ref. & Ref. \\
\hline
\end{tabular}


Table 2: Adjusted relative risk ratio (aRRR) and 95\% confidence interval of first PNC services utilization $(n=8,275)$.

\begin{tabular}{|c|c|c|c|}
\hline Variables & Category & $\begin{array}{l}\text { No PNC VS Some level of } \\
\text { PNC }(95 \% \text { CI })\end{array}$ & $\begin{array}{l}\text { No PNC VS Appropriate first } \\
\text { PNC (95\% CI) }\end{array}$ \\
\hline $\begin{array}{l}\text { Birth order } \\
\text { number }\end{array}$ & 5 or more & $0.94(0.80-1.12)$ & $0.66(0.53-0.83)^{* * *}$ \\
\hline \multirow{3}{*}{$\begin{array}{l}\text { Desire of } \\
\text { pregnancy }\end{array}$} & Desire before & $0.99(0.79-1.24)$ & $1.42(1.04-1.93)^{*}$ \\
\hline & Desire later & $0.80(0.61-1.04)$ & $1.25(0.88-1.78)$ \\
\hline & No desire & Ref. & Ref. \\
\hline \multirow{3}{*}{$\begin{array}{l}\text { Number of } \\
\text { ANC }\end{array}$} & No ANC & Ref. & Ref. \\
\hline & Less than 4 & $2.83(2.30-3.48)^{* * *}$ & $3.69(2.57-5.30)^{* * *}$ \\
\hline & 4 or more & $3.46(2.81-4.26)^{* * *}$ & $4.47(3.12-6.39)^{* * *}$ \\
\hline \multirow{3}{*}{$\begin{array}{l}\text { Place of } \\
\text { delivery }\end{array}$} & Public health facility & $3.20(2.64-3.86)^{* * *}$ & $12.50(8.16-19.16)^{* * *}$ \\
\hline & Private health facility & $4.21(3.18-5.58)^{* * *}$ & $13.50(8.27-22.05)^{* * *}$ \\
\hline & Non-health facility & Ref. & Ref. \\
\hline \multirow{3}{*}{ Birth size } & Large than average & Ref. & Ref. \\
\hline & Average & $1.14(0.98-1.32)+$ & $1.17(0.98-1.41)+$ \\
\hline & Smaller than average & $0.80(0.65-0.97)^{*}$ & $0.77(0.59-1.00)^{*}$ \\
\hline \multirow{2}{*}{ Sex of child } & Male & $0.98(0.98-1.32)$ & $0.94(0.82-1.08)$ \\
\hline & Female & Ref. & Ref. \\
\hline
\end{tabular}

$* * * \mathrm{p}<0.001, * * \mathrm{p}<0.01, * \mathrm{p}<0.05,+\mathrm{p}<0.10$

It has been documented that antenatal care exposes pregnant women to counselling and education about their own health and the care of their children and may be particularly advantageous in limiting settings like developing countries, where health seeking behaviours are inadequate, access to health services is otherwise limited, and most mothers are poor, illiterate or rural dwellers. ${ }^{25}$ Without surprise, mothers and newborns dwelling in urban areas were more likely to receive PNC visits, proved elsewhere. ${ }^{16,26}$ The higher utilization of PNC services among mothers dwelling in urban area could be linked to physical availability of services and to their socio-economic status. The majority of women in the urban area may be more economically active and even much more closed to health centres. It has been documented that improved electricity, transportation, water, and sanitation services are, on average, more widely available in urban areas, and indirectly, could enhance a mother's utilization of PNC services. ${ }^{27}$ In addition to the place of residence, differences in terms of PNC services utilization across areas where noticed as found in Tanzania., ${ }^{9,18}$

Ethnicity had an independent influence on PNC utilization in this study area as shown also in previous studies on PNC utilization and maternal health services utilization in general. ${ }^{18,25}$ This could be explained by underlying cultural beliefs and values systems of different ethnic groups which influence health perceptions, needs, and behaviour of their group members. ${ }^{18,28}$ But, elsewhere, it does constitute a mean of unequal utilization of maternal health services. ${ }^{17}$ In certain traditional societies in Benin Republic where strong beliefs remain attached to customs and traditions, a birth of a newborn infant remains a great moment of joy for the family and even for the community who, immediately after birth or after being discharged from hospital, are satisfied with traditional rites keeping mother and newborn in seclusion for long time preventing them health facility contact. Mass media use (listen to radio, watch TV and read newspapers/magazines) increase the odds of PNC services use in Benin Republic as reported elsewhere. ${ }^{29}$ Such media are the classical leading means used by health system providers in disseminating public health information, improving health knowledge and changing health behaviours. The desire of pregnancy emerged as important predictor for PNC services as reported in Tanzania and in the neighbour country, Nigeria. ${ }^{16,18}$ However, our findings showed that, the influence of this variable was remarkable in appropriate first PNC seeking. This could be explained by various advantages public enlightenment about desire for pregnancy. Once the pregnancy is desired, mother and father may be well prepared and will be more likely to welcome the newborn in joy and more preoccupied by its health and survival.

On the other hand, the extent and nature of the relationships with the number of children and birth order number were not uniform in social settings. While our findings showed a positive relationship with the number of living children (parity), as in Nigeria and reversed in Kenya, children with high birth order number (5 or above) were less likely to receive PNC check-ups, especially the appropriate ones. ${ }^{16,26}$ Increasing household income increases women's chances for PNC services seeking in Benin Republic as showed elsewhere. ${ }^{18}$ Other studies $^{9,17}$ found weak or no relationship. In many sub- 
Saharan African countries, financial hardships on one hand and the cost of medical treatments on the other hand are among the leading means preventing people from modern health systems utilization. The cost of medical treatments is also among the reasons for self-medication and the recourse to occult practices in Benin Republic. ${ }^{21}$ Against all expectation, it was found from this study that smaller than average-sized babies were less likely to be taken to health facility with their mother for PNC checkup. We expect that mothers of children with low birth weight may utilized PNC services more due to the apparent fragility of small babies. Even unexpected, this finding is in line with other study. ${ }^{16}$ While this study illuminates factors that influence utilization of PNC services by mothers in identifying possible reasons for use and non-use, further research especially qualitative one is needed for better understanding of some differences. Among other, there is a need to investigate sociocultural differences (Ethnicity, etc.) through qualitative studies. Understanding the key role of place of delivery (private health facility deliveries and public health facility deliveries) in PNC seeking behaviours through qualitative studies is also required. Such study will help understand underlying cultural beliefs and values systems, which influence PNC attendance.

To achieve the appropriate first PNC visits according to the WHO recommendation 2 in Benin Republic, our findings suggest the need to advise (counselling and education) and financially support newborn mothers and their family. The need to address unmet needs for FP and accessibility issues are also required to archive appropriate first PNC check-ups on which depends the compliance of WHO recommended PNC visits. Such understanding can help inform policy makers (Ministry of Health, Ministry of Transport and Public Works, etc.) in the formulation of national and local policies and programs to increase PNC services utilization rates, with the ultimate goal of reducing preventable maternal and newborn deaths taking place at the delivery time and beyond.

\section{Funding: No funding sources}

Conflict of interest: None declared

Ethical approval: The study was approved by the Institutional Ethics Committee

\section{REFERENCES}

1. Requejo JH, Bhutta ZA. The post-2015 agenda: staying the course in maternal and child survival. Requejo, Arch Dis Child. 2015;100(1):76-81.

2. Save the Children. Ending newborn deaths: Ensuring every baby survives. London: London ECIM 4AR, UK, 2014. Available from: http://www.savethechildren.org/site/c.8rKLIXMGIpI 4E/b.8989373/k.E376/Ending_Newborn_Deaths_En suring_Every_Baby_Survives.htm.

3. Trends in maternal mortality: 1990 to 2015. WHO, UNICEF, UNFPA, World Bank Group and the
United Nations Population Division. Geneva: World Health Organization. Available from: http://apps.who.int/iris/bitstream/10665/194254/1/97 89241565141_eng.pdf.

4. World Health Organization. WHO recommendations on Postnatal care of the mother and newborn. Geneva:2013. Available from: http://apps.who.int/iris/bitstream/10665/97603/1/978 9241506649_eng.pdf.

5. World Health Organization. WHO technical consultation on postpartum and postnatal care. Gevena: Department of Making Pregnancy Safer, 2010. Available from: http://apps.who.int/iris/bitstream/10665/70432/1/WH O_MPS_10.03_eng.pdf.

6. Lawn, J, Mongi, P et Cousens, S. Africa's newborns: counting them and making them count. Opportunities for Africa's newborns. 2006:10-22.

7. Warren C, Daly P, Toure L, Mong P. Opportunities to deliver newborn care in existing programmes: Postnatal care. in Opportunities for Africa's newborns. 2006:79-90.

8. de Graft-Johnson J, Kerber K, Tinker A, Otchere S, Narayanan I, Shoo R, et al. The maternal, newborn, and child health: continuum of care: Pratical data, policy and programmatic support for newbonr care in Africa. in Opportunities for Africa's newborns. 2006:23-36.

9. Mohan D, Gupta S, LeFevre A, Bazant E, Killewo J, Baqui AH. Determinants of postnatal care use at health facilities in rural Tanzania: Multilevel analys of household survey. BMC Pregnancy Childbirth. 2015; 15:282.

10. Darmstadt GL, Bhutta ZA, Cousens S, Adam T, Walker N, de Bernis L et al. Evidence-based, costeffective interventions: how many newborn babies can we save? Lancet. 2005;365(9463):977-88.

11. Dahiru T. Determinant of early neonatal mortality in Nigeria: Results from 2013 Nigeria DHS. J Pediatrics Neonatal Care. 2015;2.

12. Bhutta ZA, Cabral S, Chan CW, Keenan WJ. Reducing maternal, newborn, and infant mortality globally: An integrated action agenda. Int J Gynaecol Obstet. 2012;119:S13-7.

13. Ghosh R, Sharma AK. Intra-and inter-household differences in antenatal care, delivery practices and postnatal care between last neonatal deaths and last surviving children in a peri-urban area of India. J Biosoc Sci. 2010;425:511-30.

14. Paudel D, Thapa A, Shedain PR, Paudel B. Trends ans determinants of neonatal mortality in Nepal. Kathamandu, Nepal. 2013. Available from: https://dhsprogram.com/pubs/pdf/FA75/FA75.pdf

15. Titaley CR, Dibley MJ, Agho K, Roberts CL, Hall J. Determinants of neonatal mortality in Indonesia. Titaley, BMC Public Health. 2008;8:232.

16. Somefun OD, Ibisomi, L. Determinants of postnatal care non-utilization among women in Nigeria. BMC Res Notes. 2016;9:21. 
17. Lwelamira J, Safari J, Stephen A. Utilization of maternal postnatal care services among women in selected villages of Bahi Districtm Tanzania. Curr Res J Soc Sci. 2015;7(4):106-111.

18. Kanté AM, Chung CE, Larsen AM, Exavery A, Tani K, Phillips JF. Factors associated with compliance with the recommended frequency of postnatal care services in three rural districts in. BMC Pregnancy Childbirth. 2015;15:341.

19. Mill S. Reducing maternal mortality: Strengthening the World Bank Response. Maternal health text. 2009.

20. UNDP. Human development report. Sustaining Humain Progress, reducing vulnerabilities and bulding resilience. New York:2014. Available from: http://www.institutocamoes.pt/images/cooperacao/relatorio_ocde14b.pdf.

21. OCS/MGEP \& DGAE/MEF. Impacts de la gratuite des soins de sante des enfants de 0 a 5 ans et des femmes enceintes sur la pauvrete, le social et les OMD. Cotonou:2012. Available from: http://www.ageval.org/3-download/ocs-2012-AIPSsoins-sanitaires.pdf.

22. WHO. Sante development. Benin: 2009. Available from: file:///C:/Users/india/Downloads/Beninccsbrief-fr.pdf

23. Owumi B, Raji SO. Determinants of maternal health care seeking in Seme side of Benin Republic. Af J Soc Sci. 2013;145-58.

24. Richard JL. Acces et recours aux soins de santé dans la Sous-Préfecture de Ouessè (Benin). These de doctorat; 2001. Available from https://doc.rero.ch/record/474/files/these_richardjl.pd f.

25. Babalola S, Fatusi A. Determinants of use of maternal health services in Nigeria-looking beyond individual and household factors. BMC Pregnancy Childbirth. 2009;9:43.

26. Nzioki JM, Onyango RO, Ombaka JH. Sociodemographic factors influencing maternal and child health service utilization in Mwingi; a rural semiarid district in Kenya. Am J Public Health Res. 2015;3(1):21-30.

27. Fosto JC. Urban-Rural differences in child malnutrition: trends and socioeconomic correlates in sub-Saharan Africa. Health Place. 2007;13(1):20523.

28. Akoto E. Determinants Socio-culturels de la mortalite des enfants en Afrique Noire (Hypotheses et recherche d'explication). These de Doctorat, UCL. Louvain.1993. Available from: https://pulsearch.princeton.edu/catalog/813503.

29. Zamawe COF, Banda M, Dube AN. The impact of a community driven mass media campaign on the utilisation of maternal health care services in rural Malawi. BMC Pregnancy and Childbirth. 2016;16:21.

Cite this article as: Dansou J, Adekunle AO, Arowojolu AO. Factors associated with the compliance of recommended first postnatal care services utilization among reproductive age women in Benin Republic: an analysis of 2011/2012 BDHS data. Int J Reprod Contracept Obstet Gynecol 2017;6:1161-9. 